\title{
Multiple Endocrine Neoplasia Type 2B Diagnosed Early by Conjunctival Neuroma: a Case Report
}

\section{Dong-Ho Kim, Ye-Seul Jang, Sang-Rok Kang and Dong-Mee Lim}

Division of Endocrinology and Metabolism, Department of Internal Medicine, Konyang University College of Medicine, Daejeon, Korea

We would like to request a retraction of our paper entitled, 'Multiple endocrine neoplasia type 2B diagnosed early by conjunctival neuroma: a case report' by Dong-Ho Kim, Ye-Seul Jang, Sang-Rok Kang and Dong-Mee Lim from International Journal of Thyroidology. Vol 9(2): 204-209, 2016.

We regret to inform that parents of the patient want to retract this paper for private problem.

1) Kim DH, Jang YS, Kang SR, Lim DM. Multiple endocrine neoplasia type 2B diagnosed early by conjunctival neuroma: a case report. Int J Thyroidol 2016;9(2):204-9.

Correspondence: Dong-Mee Lim, MD, Division of Endocrinology and Metabolism, Department of Internal Medicine, Konyang University College of Medicine, 158 Gwanjeodong-ro, Seo-gu, Daejeon 35365, Korea

Tel: 82-42-600-9169, Fax: 82-42-600-9090, E-mail: mdldm@hanmail.net

Copyright (c) the Korean Thyroid Association. All rights reserved.

(1) ( \& This is an open-access article distributed under the terms of the Creative Commons Attribution Non-Commercial License (http://creative(c) (1) \& 8 commons.org/licenses/by-nc/4.0/), which permits unrestricted non-commercial use, distribution, and reproduction in any medium, provided the original work is properly cited. 